\title{
A rapid field-based assay using recombinase polymerase amplification for identification of Thrips palmi, a vector of tospoviruses
}

\author{
Priti $^{1} \cdot$ Sumit Jangra ${ }^{1}$ - V. K. Baranwal ${ }^{1} \cdot$ Ralf G. Dietzgen $^{2} \cdot$ Amalendu Ghosh $^{1} \mathbb{C}$
}

Received: 13 March 2020 / Revised: 11 September 2020 / Accepted: 21 September 2020 / Published online: 8 October 2020

c) Springer-Verlag GmbH Germany, part of Springer Nature 2020

\begin{abstract}
Thrips palmi (Thysanoptera: Thripidae) is an important pest of vegetables, ornamentals, and legumes worldwide. Besides damage caused by feeding, it transmits several tospoviruses. Identification of T. palmi at an early stage is crucial in implementing appropriate pest management strategies. Morpho-taxonomic identification of T. palmi based on the adult stage is time-consuming and needs taxonomic expertise. Here, we report a rapid, on-site, field-based assay for identification of $T$. palmi based on recombinase polymerase amplification (RPA), its first application in insects. RPA primers designed based on 3' polymorphisms of the Internal Transcribed Spacer 2 region efficiently discriminated T. palmi without any cross-reactivity to other predominant thrips species. RPA was performed with crude DNA, extracted from single $T$. palmi simply by crushing in sterile distilled water and could be completed within $20 \mathrm{~min}$ by holding the reaction tubes in the hand. The assay was further simplified by using fluorescent as well as colorimetric dyes thus eliminating the gel-electrophoresis steps. The presence of T. palmi was visualized by a change in color from dark blue to sky blue. The assay was validated with known thrips specimens and found to be effective in diagnosing the presence of T. palmi in natural vegetation. This on-site, rapid assay for diagnosis of $T$. palmi can be used by non-expert personnel in the field of quarantine and pest management.
\end{abstract}

Keywords RPA $\cdot$ Melon thrips $\cdot$ Insect vector $\cdot$ Tospovirus transmission $\cdot$ Thrips diagnostics

\section{Key message}

- Thrips palmi an important pest of vegetables and ornamentals transmitting several tospoviruses

- Morpho-taxonomic identification stage-specific, timeconsuming, and needs taxonomic expertise

- Rapid, on-site, field-based assay for identification of $T$. palmi using recombinase polymerase amplification

Communicated by M. Traugott .

Amalendu Ghosh

amal4ento@gmail.com

1 Insect Vector Laboratory, Advanced Centre for Plant Virology, ICAR-Indian Agricultural Research Institute, New Delhi 110012, India

2 Queensland Alliance for Agriculture and Food Innovation, The University of Queensland, St. Lucia, QLD 4072, Australia
- Assay uses crude extract of T. palmi, completed within 20 min by holding the reaction tubes in hand without use of sophisticated laboratory instruments

- The presence of T. palmi visualized by a change in reaction color

- Useful for non-expert personnel in field-based identification, quarantine, and adopting suitable pest management strategies

\section{Introduction}

Thrips (order Thysanoptera) are important agricultural pests that cause significant losses in yield and quality of agricultural products worldwide. These small insects cause damage to leaves, flowers, and fruits by feeding and sometimes induce galls. Distinctive silvery scarring on the leaves, stems, or fruits is often visible due to their feeding (Trdan et al. 2007; Chisholm and Lewis 2009; Ghosh et al. 2009, 2017). Besides the direct damage, thrips also transmit economically damaging tospoviruses (family Tospoviridae, order Bunyavirales) (Rotenberg et al. 
2015). Thrips-transmitted tospoviruses cause significant economic losses in a large number of plant families (Pappu et al. 2009).

Melon thrips (Thrips palmi Karny, Thysanoptera: Thripidae) is a key pest in vegetables, legumes, and ornamentals, transmitting more than 7 different tospoviruses (Rotenberg et al. 2015). The distribution of T. palmi was thought to be restricted to Southern Asia, but in recent decades it has been observed throughout Asia. It is considered a predominant tospovirus vector in Asia (Mandal et al. 2012). Groundnut bud necrosis virus is transmitted by T. palmi and causes losses of more than US $\$ 89$ million per annum across Asia (Reddy et al. 1995; Jagdale and Ghosh 2019, Ghosh et al. 2019). It has widely invaded the Pacific, Florida, the Caribbean, South America, Africa, and Australia (Bhatti 1980; Johnson 1986; Guyot 1988; Pantoja et al. 1988; Cooper 1991; Palmer 1992; Monteiro et al. 1995; EPPO 2014; Jangra et al. 2020a, Ghosh et al. 2020). T. palmi and the viruses it transmits are not yet established in Europe and it is listed as a quarantine pest by EPPO (2014). T. palmi continues to pose a significant risk to agricultural production and has the potential to cause significant economic losses to a wide range of fieldas well as glasshouse-grown crops. Diagnosis of T. palmi at an early stage of infestation is therefore necessary for adopting suitable pest management strategies and quarantine measures. Morphological key-based identification of T. palmi based on the adult stage is time-consuming and demands taxonomic expertise (Mehle and Trdan 2012). Nucleic acid- and protein-based techniques such as polymerase chain reaction (PCR), random amplified polymorphic DNA (RAPD), restriction fragment length polymorphism (RFLP), sequence characterized amplified regions (SCAR) markers, real-time PCR, loop-mediated isothermal amplification (LAMP), and monoclonal antibodies have been used for identification of T. palmi (Paran and Michelmore 1993; Banks et al 1998; Walsh et al. 2005; Yeh et al. 2014; Nakahara and Minoura 2015; Przybylska et al. 2015). PCR-based techniques are not useful for the field-based diagnosis of T. palmi. LAMP is simpler than PCR but it requires nucleic acid extraction and higher temperature that may not be feasible at field conditions. Thus, we have developed an on-site, field-based rapid assay for accurate identification of $T$. palmi without the need for sophisticated laboratory equipment, based on recombinase polymerase amplification (RPA). The RPA assay includes three core enzymes viz. recombinase, single-stranded DNA binding protein, and strand-displacing polymerase, and is highly efficient in the diagnosis of zoonotic diseases and plant viruses (Li et al. 2019; Xi et al. 2019; Ma et al. 2019a, b; Cha et al. 2020). This is the first experimental demonstration where RPA has been successfully used for the identification of an insect species.

\section{Materials and methods}

\section{Establishment of a homogenous population of $T$. palmi}

The initial population of T. palmi was collected from a stock population maintained at Advanced Centre for Plant Virology, Indian Agricultural Research Institute (IARI), New Delhi. The identity was confirmed by morphometric keys (Bhatti 1980; Cluever and Smith 2017) and sequencing mitochondrial cytochrome oxidase subunit I (mtCoI). To develop a homogenous population, a single adult female of T. palmi was released on healthy brinjal (Solanum melongena var. Navkiran) plants under controlled conditions at $28 \pm 1{ }^{\circ} \mathrm{C}$ temperature, $60 \pm 10 \%$ relative humidity, and $8 \mathrm{~h}$ dark. Fresh plants were provided in the rearing cages as and when required. Adults were collected from the iso-female population with a fine Camel hairbrush for further experiments.

\section{DNA extraction from T. palmi}

Total DNA was extracted from T. palmi using a cetyltrimethylammonium bromide (CTAB) method. CTAB extraction buffer was prepared in a total volume of $10 \mathrm{ml}$ by adding $3.5 \mathrm{ml}$ of $10 \%$ CTAB, $1 \mathrm{ml}$ of $1 \mathrm{M}$ Tris- $\mathrm{HCl}, 400 \mu \mathrm{l}$ of $0.5 \mathrm{M}$ EDTA (pH 8.0), $2.8 \mathrm{ml}$ of $5 \mathrm{M} \mathrm{NaCl}, 20 \mu \mathrm{l}$ 2-mercaptoethanol, and $2.28 \mathrm{ml}$ nuclease-free water. A single adult thrips was collected in a $1.5-\mathrm{ml}$ micro-centrifuge tube and crushed in $100 \mu \mathrm{l}$ of CTAB extraction buffer with a micropestle. The lysate was vortexed and incubated at $65^{\circ} \mathrm{C}$ for $30 \mathrm{~min}$. An equal volume of chloroform: isoamyl alcohol $(24: 1)$ was added to the lysate, mixed, and centrifuged at $14,000 \times g$ for $15 \mathrm{~min}$. The upper aqueous phase was transferred to a new micro-centrifuge tube. The DNA was precipitated by adding 0.7 volumes of ice-cold isopropanol and kept at $-20^{\circ} \mathrm{C}$ for $1 \mathrm{~h}$. The sample was centrifuged at $14,000 \times g$ for $10 \mathrm{~min}$ and the supernatant was decanted gently. The pellet, if any, was washed with $100 \mu \mathrm{l}$ of $70 \%$ ethanol. The ethanol was decanted and residual ethanol was removed by drying at room temperature. The DNA pellet was dissolved in $50 \mu \mathrm{l}$ sterile distilled water and used for further experiments.

\section{Designing T. palmi-specific primers for RPA}

The primers used in this study were designed following TwistAmp ${ }^{\circledR}$ assay design manual guidelines (https:// www.twistdx.co.uk). Three pairs of RPA primers (Table 1) were designed based on the sequence polymorphism of Internal Transcribed Spacer 2 (ITS2) region of T. palmi. All ITS2 sequences of T. palmi available at the National Center for Biotechnology Information (NCBI) were utilized 
Table 1 List of RPA primers used for amplification of ITS2 region of T. palmi

\begin{tabular}{|c|c|c|c|c|c|}
\hline \multicolumn{2}{|c|}{ Forward primer } & \multicolumn{2}{|c|}{ Reverse primer } & \multirow{2}{*}{$\begin{array}{l}\text { Observed } \\
\text { amplicon size } \\
\text { (bp) }\end{array}$} & \multirow{2}{*}{$\begin{array}{l}\text { Annealing } \\
\text { tempera- } \\
\text { ture }\end{array}$} \\
\hline Name & Sequence $\left(5^{\prime} \rightarrow 3^{\prime}\right)$ & Name & Sequence $\left(5^{\prime} \rightarrow 3^{\prime}\right)$ & & \\
\hline AG113F & $\begin{array}{l}\text { AAAACGGGGAAAGGCCTTGCAAAG } \\
\text { GAAAAATC }\end{array}$ & AG114R & $\begin{array}{l}\text { GAATCGGAGCGAGGAGGCATTTAA } \\
\text { GAGATCCAC }\end{array}$ & 280 & $72{ }^{\circ} \mathrm{C}$ \\
\hline AG115F & $\begin{array}{l}\text { TTGCGATGTGTCTCTGCACGCGCC } \\
\text { CATCG }\end{array}$ & AG116R & $\begin{array}{l}\text { CGACTACAGAGAACGGGAAACACA } \\
\text { CAACGG }\end{array}$ & 200 & $67.4{ }^{\circ} \mathrm{C}$ \\
\hline AG117F & $\begin{array}{l}\text { CTGGACTTGCTCTCACGGGCGAGTCCT } \\
\text { CCC }\end{array}$ & AG118R & $\begin{array}{l}\text { AAGCGGAAATCCACTCTCGCGTGC } \\
\text { ACGG }\end{array}$ & 290 & $75^{\circ} \mathrm{C}$ \\
\hline
\end{tabular}

for primer-design. The conserved region of T. palmi ITS2 was chosen to cover all known intra-specific variants of $T$. palmi. Sites with a mismatch at 3 '-end sequences among the congeneric thrips species were targeted to design the species-specific primers. The major characteristics such as primer length, amplicon size, GC contents, and intra-primer or inter-primer homology were taken into consideration. The site-specificity of the primers was verified by PrimerBLAST (https://www.ncbi.nlm.nih.gov). FastPCR (version 6.6.99) was done with available ITS2 sequences of thrips species in NCBI to analyze the in-silico specificity and cross-reactivity of the primers.

\section{Conventional PCR with T. palmi RPA primers}

Conventional PCR was carried out in a $25 \mu \mathrm{l}$ reaction mixture to validate the newly designed RPA primers. Each reaction contained $1 \mu \mathrm{l}$ of $10 \mathrm{mM}$ each forward and reverse primers (Eurofins), $260 \mu \mathrm{M}$ dNTP mix (Thermo Fisher Scientific), $2.5 \mu \mathrm{l}$ of $10 \times$ PCR buffer (Thermo Fisher Scientific), 20 ng DNA template, and 2U DreamTaq DNA polymerase (Thermo Fisher Scientific). PCR was done in a T100 Thermal Cycler (Bio-Rad) with one cycle at $94{ }^{\circ} \mathrm{C}$ for $3 \mathrm{~min}, 35$ cycles of $94{ }^{\circ} \mathrm{C}$ for $30 \mathrm{~s}$, annealing at $63{ }^{\circ} \mathrm{C}$ $-78{ }^{\circ} \mathrm{C}$ depending upon the primer pairs for $50 \mathrm{~s}, 72{ }^{\circ} \mathrm{C}$ for $50 \mathrm{~s}$, and a final extension at $72{ }^{\circ} \mathrm{C}$ for $10 \mathrm{~min}$. PCR products were resolved on $2 \%$ agarose gel stained with GoodView ${ }^{\mathrm{TM}}$ (BR Biochem) and visualized in a gel documentation system (MasteroGen Inc, Taiwan) with 100 bp Plus DNA ladder (Thermo Fisher Scientific).

\section{Recombinase polymerase amplification}

RPA was done using newly designed primer pairs at a temperature range of $35-41{ }^{\circ} \mathrm{C}$. The assay was carried out in a reaction volume of $25 \mu \mathrm{l}$ following the protocol as outlined in the TwistAmp® Basic kit (TwistDx, Cambridge, UK) with slight modifications. The reaction mixture of $45.5 \mu \mathrm{l}$ was prepared by adding $2.5 \mu \mathrm{l}$ of each forward and reverse primers $(10 \mathrm{mM}), 29.5 \mu \mathrm{l}$ rehydration buffer, and $11 \mu \mathrm{l}$ nuclease-free water. The contents were mixed with the freeze-dried reaction provided in TwistAmp Basic and then distributed into 2 reaction tubes. Next, $1 \mu \mathrm{l}$ of $T$. palmi DNA template $(\sim 20 \mathrm{ng})$, and $1.25 \mu \mathrm{l}$ of $280 \mathrm{mM}$ magnesium acetate was added to the reaction and mixed gently by pipetting. The reaction mix was then incubated at a temperature gradient of $35{ }^{\circ} \mathrm{C}-41{ }^{\circ} \mathrm{C}$ in a heating block for $20 \mathrm{~min}$. The amplified products were resolved on $2 \%$ agarose gel stained with GoodView ${ }^{\mathrm{TM}}$ and visualized in a gel documentation system with 100 bp Plus DNA ladder.

\section{Cross-reactivity assay for RPA primers}

The specificity of the RPA primer pairs for T. palmi and potential cross-reactivity with other congeneric thrips species were assessed by PCR. PCR was done using primer pairs AG113F-AG114R, AG115F-AG116R, and AG117FAG118R separately with DNA templates of T. palmi, T. tabaci Lindeman, and Scirtothrips dorsalis Hood. PCR was done in $25 \mu \mathrm{l}$ reaction volumes and amplicons were resolved by $2 \%$ agarose gel electrophoresis as described above.

Cross-reactivity of the primer pairs was also assessed by RPA in $25 \mu \mathrm{l}$ reaction volumes at $37{ }^{\circ} \mathrm{C}$ and products were resolved on $2 \%$ agarose gel as described above. Primer pairs that showed any amplification with DNA templates of other thrips species were not considered further. The primer pair that was not cross-reactive to other predominant thrips species in both PCR and RPA, and that resolved well on agarose gels, was progressed further to develop a standardized field-based assay.

\section{On-site crude DNA extraction}

To develop an on-site rapid DNA extraction protocol, different methods for crude DNA extraction from single $T$. palmi were evaluated. Crude DNA was extracted by crushing single T. palmi adult in ethylenediaminetetraacetic acid (EDTA), phosphate-buffered saline (PBS), or sterile distilled water. A single T. palmi adult was transferred into a $1.5-\mathrm{ml}$ micro-centrifuge tube with the help of a fine Camel hairbrush. Thirty $\mu \mathrm{l}$ of $0.02 \mathrm{M}$ EDTA $(\mathrm{pH}$ 8.0) was added and the sample was crushed within the micro-centrifuge tube 
using a sterile micropestle. Similarly, samples were crushed in PBS (pH 7.4) or sterile distilled water. Tubes were incubated in boiling water $\left(100{ }^{\circ} \mathrm{C}\right)$ for $10 \mathrm{~min}$. The quality and quantity of crude DNA extracted through these methods were determined by spectrophotometer (NanoDrop ${ }^{\mathrm{TM}}$ One, Thermo Fisher Scientific). Further, PCR was done using the DNA of T. palmi extracted through these methods as templates. Twenty-five $\mu \mathrm{l}$ of each PCR mixture contained $1 \mu \mathrm{l}$ of $10 \mathrm{mM}$ each forward and reverse primer (AG117FAG118R), $260 \mu \mathrm{M}$ dNTP mix, $2.5 \mu \mathrm{l}$ of $10 \times$ PCR buffer, 20 ng DNA template, and 2U DreamTaq DNA polymerase. Thermal cycling was done in a T100 Thermal Cycler with one cycle of $94{ }^{\circ} \mathrm{C}$ for $3 \mathrm{~min}, 35$ cycles of $94{ }^{\circ} \mathrm{C}$ for $30 \mathrm{~s}$, $75^{\circ} \mathrm{C}$ for $50 \mathrm{~s}, 72{ }^{\circ} \mathrm{C}$ for $50 \mathrm{~s}$, and a final extension at $72{ }^{\circ} \mathrm{C}$ for $10 \mathrm{~min}$. PCR products were resolved on $2 \%$ agarose gel as described above. The crude extract that provided the best PCR amplification comparable to CTAB-extracted DNA was used in RPA assay to identify T. palmi.

\section{Sensitivity of RPA assay}

The sensitivity of RPA was determined with primer pair AG117F-AG118R using ten-fold serially diluted $\left(2 \times 10^{2}-2 \times 10^{-12} \mathrm{ng}\right)$ crude DNA of T. palmi. RPA was done as described above. Based on the results of RPA using a temperature gradient, the reaction was incubated at $37^{\circ} \mathrm{C}$. The amplified products were resolved on $2 \%$ agarose gel as described above. The sensitivity of RPA using crude DNA extracts of T. palmi was compared with that of PCR using serially-diluted crude DNA of T. palmi in $25 \mu \mathrm{l}$ reaction volume and resolved on $2 \%$ agarose gel as described above.

\section{Field-based end-point detection of RPA}

To eliminate the gel electrophoresis step used to visualize RPA results in the laboratory, different fluorescence, and colorimetric methods were evaluated. RPA was done as described above using crude DNA of T. palmi as positive control along with a non-template control. The reaction was incubated at body temperature $\left(\sim 37^{\circ} \mathrm{C}\right)$ by holding the tubes in the hand (Fig. 1). The fluorescent nucleic acid dye SYBR Green I (Thermo Fisher Scientific) was added after completion of reaction at $0.1 \mu \mathrm{l}$ per tube. Keeping in mind the cost of SYBR Green dye, the RPA assay was also evaluated by adding $0.5 \mu \mathrm{l}$ of GoodView ${ }^{\mathrm{TM}}$ stain after completion of the reaction. The appearance of fluorescence under UV light was noted to determine the presence of T. palmi.

Both these fluorescence-based end-point detection assays required use of a UV torch or transilluminator which may not be feasible in the field. Therefore, we used a colorimetric detection of RPA using hydroxynaphthol blue (HNB, Sisco Research Laboratories Pvt. Ltd. India) dye. RPA reaction was done in $25 \mu \mathrm{l}$ reaction volume as described above and $1 \mu \mathrm{l}$ of $3 \mathrm{mM} \mathrm{HNB}$ was added before amplification and mixed well by pipetting. The reaction was incubated at $37^{\circ} \mathrm{C}$ by holding the tubes in hand. A change in color was seen after 20 min of incubation indicative of the presence of $T$. palmi.
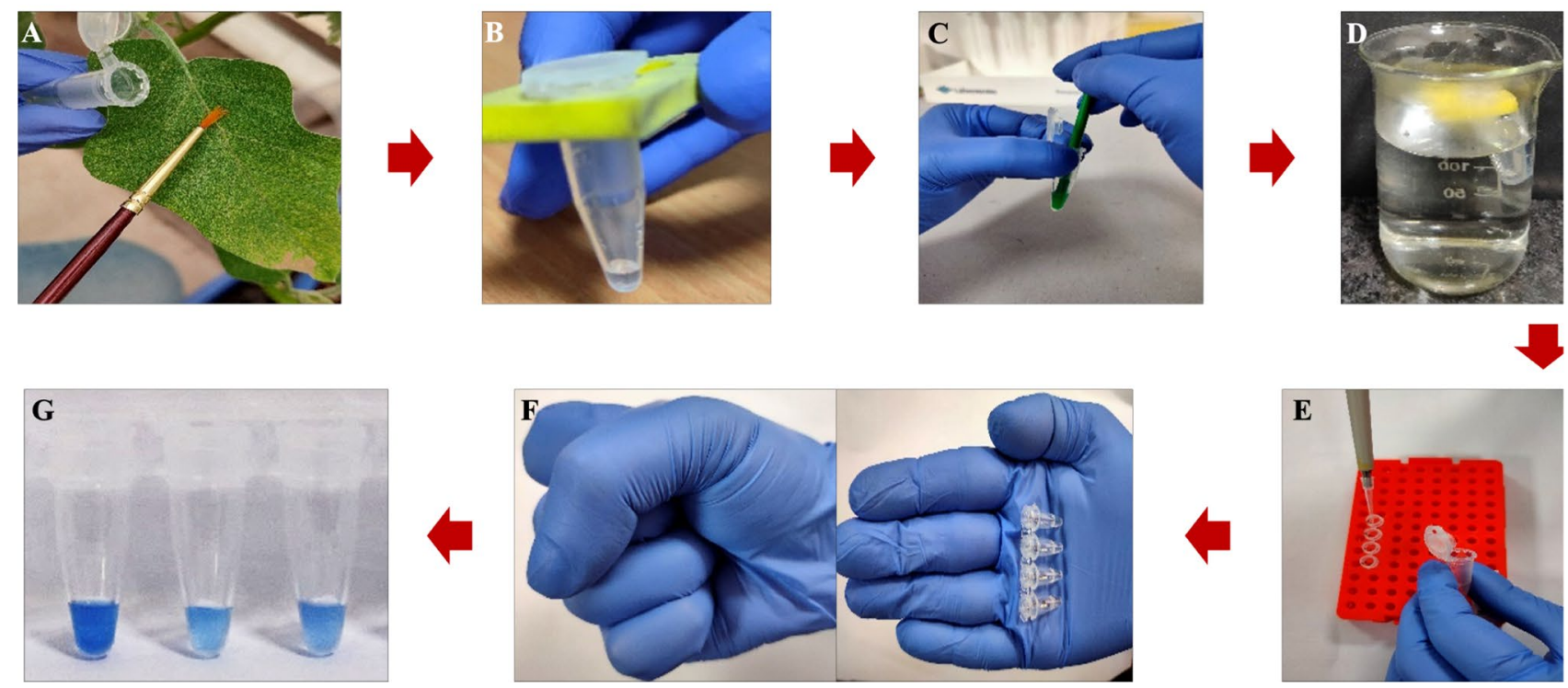

Fig. 1 Workflow of the RPA assay for on-site rapid identification of T. palmi. a Collection of single thrips into a micro-centrifuge tube, $\mathbf{b}$ addition of $30 \mu \mathrm{l}$ sterile distilled water, $\mathbf{c}$ manually crushing of thrips with a micropestle, $\mathbf{d}$ placing in boiling water for $10 \mathrm{~min}$, $\mathbf{e}$ addition of $1 \mu \mathrm{l}$ extract to $25 \mu \mathrm{l}$ TwistAmp® basic reaction mixture in mini strip tubes, $\mathbf{f}$ holding the reaction tubes in fist for $20 \mathrm{~min}$, $\mathbf{g}$ visual assessment of results. Change in reaction color from dark blue to sky blue indicates presence of T. palmi 


\section{Validation of RPA assay}

The standardized RPA described above was validated with a large number of known thrips specimens. Further, the assay was used to identify T. palmi in natural vegetation at IARI experimental farm. Thrips DNA from unknown specimens was extracted in sterile distilled water on-site. The RPA reaction was carried out using HNB by holding the tubes in hand for $20 \mathrm{~min}$. The presence of T. palmi was identified based on the change in reaction mix color from dark blue (negative) to sky blue (positive). MtCOI region of representative positive and negative samples was amplified by PCR with primer pair LCO-1490, and HCO-2198 (Folmer et al. 1994) and directly sequenced for further confirmation.

\section{Results}

\section{Standardization of primers and RPA conditions}

Three primer pairs viz. AG113F-AG114R, AG115FAG116R, and AG117F-AG118R were designed based on sequence polymorphisms of the ITS2 region; primers were 30-35 nucleotides long (Table 1). The GC content in all these primers was moderate (43.75-66.67\%). The primer pairs showed a low probability to form secondary structures and primer-primer interactions or hairpins in Primer-BLAST analysis. Primer-BLAST also ensured the specificity of the primers for ITS2 region of T. palmi and could amplify the intra-specific variants of T. palmi. The output of FastPCR with the primer pairs AG113F-AG114R, AG115F-AG116R, and AG117F-AG118R showed amplicons of calculated sizes $283 \mathrm{bp}, 209 \mathrm{bp}$, and $282 \mathrm{bp}$ for T. palmi at a predicted annealing temperature of $70{ }^{\circ} \mathrm{C}, 70{ }^{\circ} \mathrm{C}$, and $72{ }^{\circ} \mathrm{C}$, respectively, without any cross-reactivity to other congeneric thrips species.

In gradient PCR, all primer pairs amplified products of ITS2 of T. palmi. Sharp bands of $\sim 280 \mathrm{bp}$ and $200 \mathrm{bp}$ were obtained in the PCR with primer pairs AG113F-AG114R and AG115F-AG116R at annealing temperatures of $73{ }^{\circ} \mathrm{C}$ and $67.4^{\circ} \mathrm{C}$, respectively. The primer pair AG117F-AG118R showed the strongest amplification of 290 bp at $75{ }^{\circ} \mathrm{C}$ annealing temperature.

RPA assay using the three primer pairs showed amplification of about $280 \mathrm{bp}, 200 \mathrm{bp}$, and $290 \mathrm{bp}$ at a temperature range of $35^{\circ} \mathrm{C}-41^{\circ} \mathrm{C}$. Although amplification was satisfactory across this temperature range, incubation at $37^{\circ} \mathrm{C}$ was considered best to proceed with the field-based assay. As the normal human body temperature is about $37{ }^{\circ} \mathrm{C}$, standardizing the RPA assay at this temperature enabled performing the reaction by holding the tubes in one's hand and eliminated the requirement of a heating block.

\section{Cross-reactivity of RPA primers with other predominant thrips species}

In PCR assay, primer pair AG113F-AG114R showed crossreactivity with $S$. dorsalis. An amplicon of $\sim 280$ bp was observed with both T. palmi and S. dorsalis DNA templates. PCR with primer pair AG115F-AG116R using DNA templates of T. palmi, T. tabaci, and S. dorsalis did not show any amplification for $S$. dorsalis but amplified a product of $\sim 200 \mathrm{bp}$ from both T. palmi and T. tabaci (data not shown). However, primer pair AG117F-AG118R amplified a product of $\sim 290 \mathrm{bp}$ from DNA template of T. palmi only and no amplification occurred from DNA templates of other thrips species tested that are predominant in India (Fig. 2a). The results of the RPA assay with primer pairs AG113FAG114R and AG115F-AG116R mirrored those of the PCR assay. On the other hand, primer pair AG117F-AG118R did not show any cross-reactivity with DNA of other thrips species in RPA and yielded an amplicon of $\sim 290 \mathrm{bp}$ for T. palmi template only (Fig. 2b). Since the primer pair AG117FAG118R was specific for T. palmi and did not yield an amplicon from congeneric thrips species, it was considered useful for on-site detection of T. palmi based on RPA.

\section{On-site crude DNA preparation from T. palmi}

The on-site crude DNA extraction minimized processing times and did not require sophisticated laboratory equipment otherwise essential for DNA extraction using the CTAB method. The maximum amount of total DNA from a single adult of $T$. palmi extracted in PBS was approximately $1100( \pm 120) \mathrm{ng}$. About $700( \pm 110) \mathrm{ng}$ and $500( \pm 30) \mathrm{ng}$ crude DNA were extracted in distilled water and EDTA, respectively. The mean absorbance 260/280 values were recorded as 1.3, 1.4, and 1.9 for the DNA extracted in PBS, distilled water, and EDTA, respectively. A 260/230 ratio of the extracted DNA extracted in EDTA (0.06) indicated the presence of contaminants.

PCR with primer pair AG117F-AG118R produced clear and sharp bands of $290 \mathrm{bp}$ in $2 \%$ agarose gel for the DNA templates extracted in distilled water and PBS (Fig. 3). The quality of PCR amplification using DNA extracted in distilled water and PBS was best and comparable to PCR amplification using DNA extracted by the CTAB method. No amplicons were observed following PCR with thrips DNA extracted in EDTA. DNA extraction using distilled water did not require any buffer preparation and was therefore considered easiest for RPA assays in the field.

\section{Sensitivity of RPA assay}

To determine the assay sensitivity using primer pair AG117F-AG118R, RPA was applied to a serial dilution 


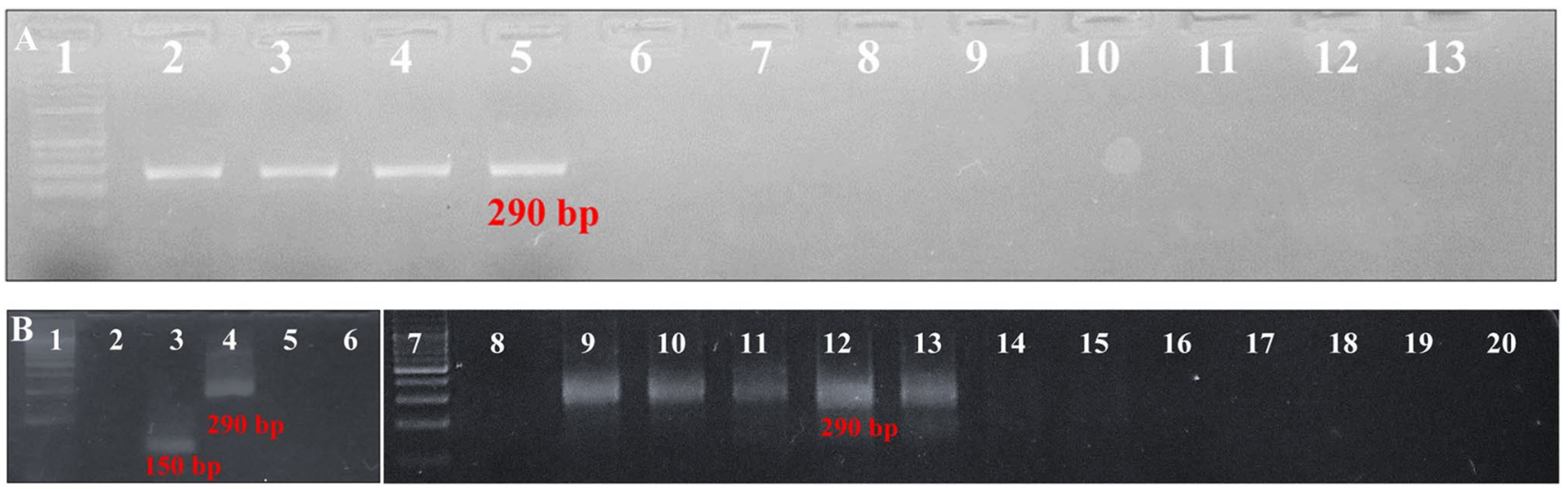

Fig. 2 Assessment of potential cross-reactivity of $T$. palmi-specific primer pair AG117F and AG118R. a 2\% agarose gel electrophoresis to resolve PCR amplicons. Lane 1: 100 bp plus DNA ladder; Lanes 2-12: PCR amplicons using DNA extracts of T. palmi (2-5), T. tabaci (6-9), and S. dorsalis (10-12); Lane 13: no-template control. PCR yielded a single band of $290 \mathrm{bp}$ for T. palmi only. b $2 \%$ agarose gel electrophoresis showing RPA results. Lane 1 and 7: 100 bp plus DNA ladder, Lane 2 and 8: no-template control, Lane 3: positive control provided with TwistAmp® Basic kit, Lanes 4-6 and 9-20: RPA products using DNA extracts of T. palmi $(4,9-13)$, S. dorsalis $(5,18-20)$, and $T$. tabaci $(6,14-17)$. RPA yielded a single $290 \mathrm{bp}$ band for $T$. palmi. No amplification was observed with T. tabaci and S. dorsalis templates. The positive kit control yielded $\sim 150 \mathrm{bp}$ amplicon

\section{Field-based end-point detection RPA assay}

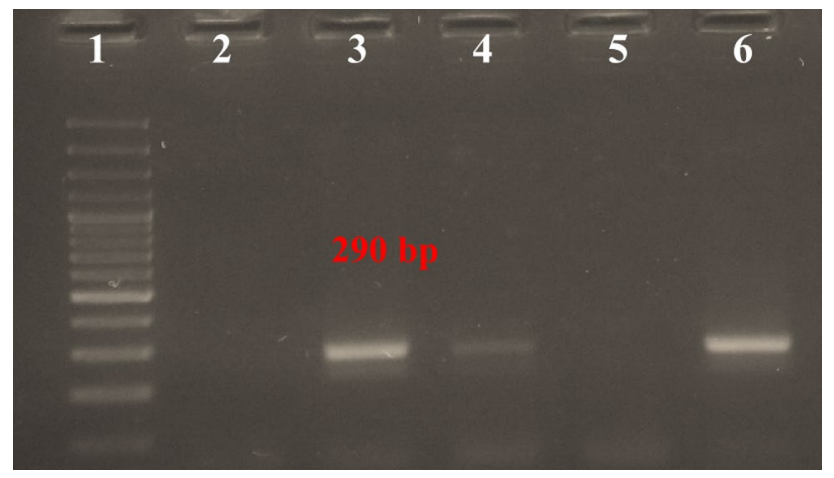

Fig. 3 PCR with DNA templates of $T$. palmi extracted by different methods. Lane 1: 100 bp plus DNA ladder, Lane 2: no-template control, Lane 3-6: PCR amplicons with T. palmi template extracted in sterile distilled water (3), PBS (4), EDTA (5), and CTAB (6). PCR with template extracted in EDTA did not yield any amplicons. Single amplicons of 290 bp were observed following PCR using thrips ground in sterile distilled water, PBS and CTAB

series of T. palmi DNA extracted in distilled water. Amplicons of $\sim 290$ bp were seen by gel electrophoresis following RPA of T. palmi input DNA of between $200 \mathrm{ng}$ and $2 \times 10^{-10} \mathrm{ng}$ (Fig. 4). PCR with primer pair AG117F-AG118R amplified the corresponding product up to $2 \times 10^{-1}$ ng of DNA template extracted in distilled water. This shows that the RPA assay for identification of T. palmi was $10^{9}$ times more sensitive than PCR and could detect as little as $0.2 \mathrm{ag}\left(2 \times 10^{-19} \mathrm{~g}\right)$ of DNA.
To use the RPA assay in an on-site field situation, agarose gel electrophoresis was replaced by fluorescent and colorimetric dyes. RPA assay showed distinct fluorescence by UV illumination in the reaction tubes in positive samples ( $T$. palmi DNA) when SYBR Green I was added, whereas no fluorescence was observed in negative samples (Fig. 5a). Addition of GoodView ${ }^{\mathrm{TM}}$ into the reaction mix after RPA also showed fluorescence in the samples that contained $T$. palmi DNA, whereas no fluorescence was observed in the negative samples under a UV light (Fig. 5b). The RPA assay with HNB dye changed color from dark blue (negative) to sky blue (positive) for samples that contained T. palmi DNA (Fig. 5c), whereas no such color change was observed in negative samples.

\section{Identification of thrips from natural vegetation}

The RPA assay was validated with more than 60 specimens ( 30 T. palmi, $\sim 15$ each of T. tabaci, and S. dorsalis) of known thrips. The results confirmed the test-retest reliability and reproducibility of the assay (Fig. 6). RPA was then used to identify $T$. palmi from natural vegetation by extracting DNA in distilled water on-site and adding HNB to the reaction mix. In more than 30 collections from natural vegetation, T. palmi was identified in 17 samples collected from cucumber, brinjal, cotton, lettuce, soybean, mungbean, and sponge gourd plants. A change in reaction mix color from dark blue to sky blue after holding in one's hand for $20 \mathrm{~min}$ indicated the presence of T. palmi in the test samples (Fig. 7). The reactions with thrips samples collected 


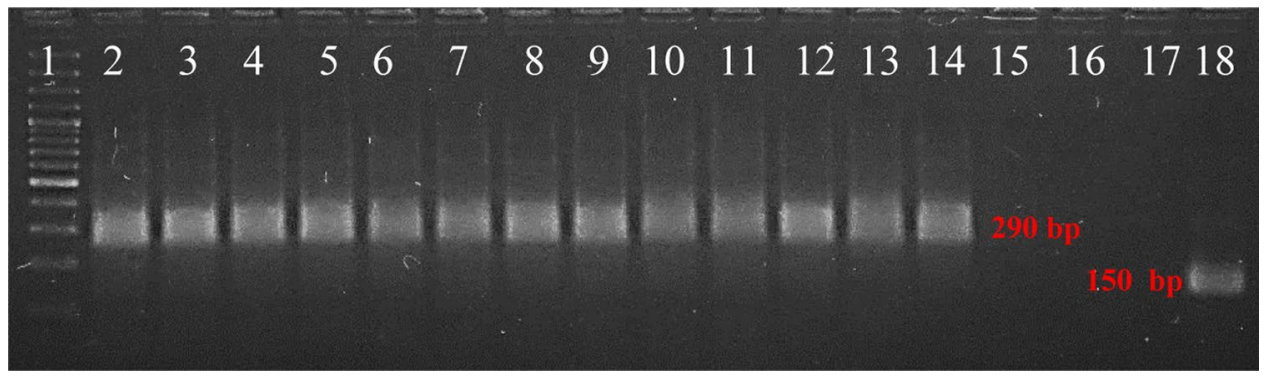

Fig. 4 Sensitivity of the RPA assay using primer pair AG117F and AG118R. Serially ten-fold diluted T. palmi DNA extracted in sterile distilled water was used as template and products resolved on 2\% agarose gel. Lane 1: 100 bp plus DNA ladder, Lanes 2-16: RPA product with T. palmi template of $2 \times 10^{2} \mathrm{ng}(2), 2 \times 10^{1} \mathrm{ng}$ (3), $2 \mathrm{ng}$
(4), $2 \times 10^{-1} \mathrm{ng}(5), 2 \times 10^{-2} \mathrm{ng}(6), 2 \times 10^{-3} \mathrm{ng}(7), 2 \times 10^{-4} \mathrm{ng}(8)$, $2 \times 10^{-5} \mathrm{ng}(9), 2 \times 10^{-6} \mathrm{ng}(10), 2 \times 10^{-7} \mathrm{ng}(11), 2 \times 10^{-8} \mathrm{ng}(12)$, $2 \times 10^{-9} \mathrm{ng}(13), 2 \times 10^{-10} \mathrm{ng}(14), 2 \times 10^{-11} \mathrm{ng}(15), 2 \times 10^{-12} \mathrm{ng}$ (16), Lane 17: no-template control, Lane 18: 150 bp product positive kit control
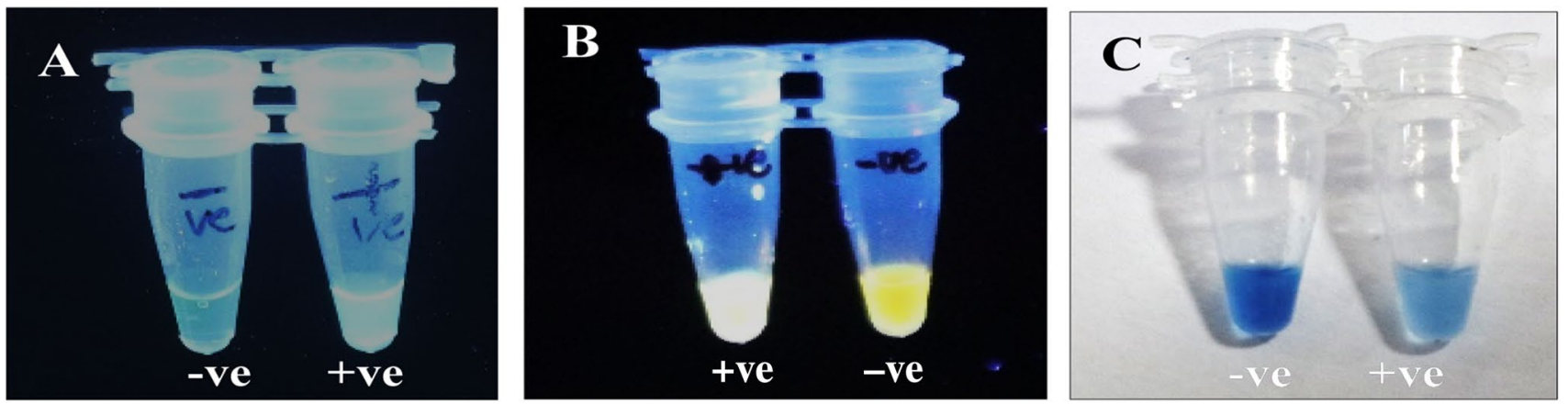

Fig. 5 Visualization of RPA products using a. SYBR Green I, b. GoodView ${ }^{\mathrm{TM}}$, and c. Hydroxynaphthol blue (HNB). RPA was done using crude DNA of T. palmi as positive $(+)$ and water as negative (-) samples in $25 \mathrm{ul}$ reactions. Addition of SYBR Green and GoodView $^{\mathrm{TM}}$ at 0.1 and $0.5 \mu \mathrm{l}$, respectively, after completion of the reactions showed fluorescence under UV illumination only in the posi- tive sample containing $T$. palmi template while no fluorescence was observed in the negative samples. The RPA mixed with $1 \mu \mathrm{l}$ of $3 \mathrm{mM}$ HNB added prior to amplification showed a change in color from dark blue to sky blue in the case of T. palmi DNA, whereas no corresponding change was observed in the negative sample

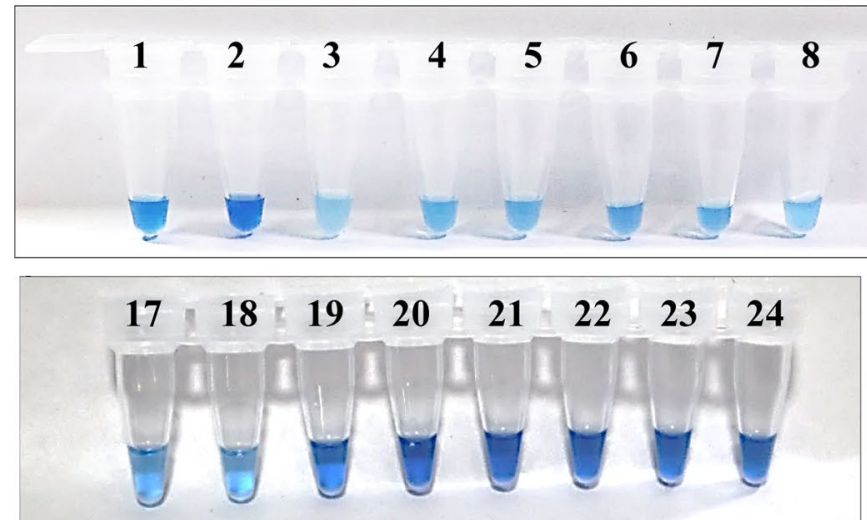

Fig. 6 RPA assay for field-based identification of T. palmi. RPA was done using primer pair AG117F and AG118R with extracts of known thrips species. Hydroxynaphthol blue was added prior to amplification. Tube 1, 19-21: T. tabaci; Tube 2, 22-24: S. dorsalis; Tube 3-15,
17-18: T. palmi, Tube 16: no-template control. RPA clearly discriminated $T$. palmi from other tested thrips species by a change in reaction color from dark blue to sky blue 


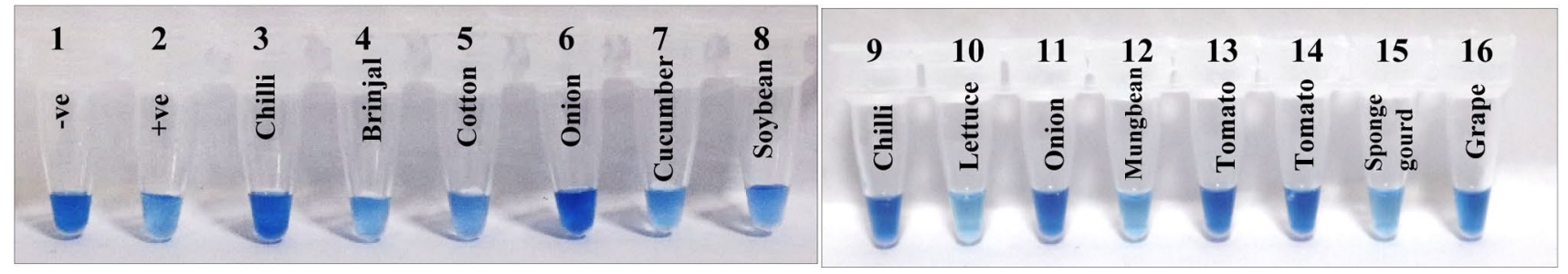

Fig. 7 Identification of T. palmi collected from different crop species using the RPA assay. DNA was extracted in sterile distilled water on-site. RPA assay was performed with primer pair AG117F and AG118R. 1: no-template control, 2: T. palmi DNA positive control. 3-8: unknown thrips collected from chilli $(3,9)$, brinjal (4), cotton (5), onion $(6,11)$, cucumber (7), soybean (8), lettuce (10), mungbean (12), tomato $(13,14)$, sponge gourd (15), and grape (16). The RPA

from chilli, onion, tomato, and grape did not show any color change indicating that the collected thrips were not T. palmi. The sequences of mtCOI further confirmed the identity of the positive samples as T. palmi and negative samples as T. tabaci (four samples), $S$. dorsalis (six samples), and $F$. schultzei (three samples). The sequences are available in NCBI with the accession numbers given in the data availability section.

\section{Discussion}

RPA is an isothermal alternative to PCR. RPA assay utilizes three components viz. recombinase, single-strand DNA binding protein, and a strand-displacing polymerase. Recombinase forms a complex with the RPA primers and assists in binding the homologous sequence of DNA. Single strand binding protein binds to a displaced strand and stabilizes the subsequently formed D loop of the duplex. Strand-displacing polymerase begins the extension from the primers only if the target sequence is present. This technique has been successfully used for diagnosis of animal and human diseases including porcine coronavirus in piglets, Pasteurella multocida in cattle, Schistosoma haematobium in humans, and zoonotic diseases caused by Mycobacterium avium subsp. paratuberculosis (Rosser et al. 2015; Hansen et al. 2016; Zhao et al. 2019; Ma et al. 2019a, b). RPA has also been used in the diagnosis of plant pathogens including banana bunchy top virus, little cherry virus 2 , and citrus greening bacterium (Mekuria et al. 2014; Londono et al. 2016; Kapoor et al. 2017; Ghosh et al. 2018). However, RPA has not been exploited so far to identify any insect species. This is the first report of a field-based assay for the detection of T. palmi based on RPA.

Thrips palmi is a major insect pest of vegetable and ornamental crops worldwide and a major vector for transmitting several tospoviruses (Ghosh et al. 2019, Jangra et al. 2020a). It is a predominant tospovirus vector in Asia and assay showed the change in color from dark blue to sky blue with DNA of thrips collected from brinjal, cotton, cucumber, soybean, lettuce, mungbean, and sponge gourd plants indicating infestation with T. palmi. No change in color with DNA of thrips collected from chilli, onion, tomato, and grape plants confirmed that different thrips species were present

also invaded Africa, America, and Australia (Houston et al. 1991; Cermeli and Montagne 1993; Murai 2002; Yadav and Chang 2012; Seal et al. 2013). T. palmi was detected in glasshouses in the Netherlands in 1988 and 1992 (Mound and Gillespie 1997) and subsequently eradicated by destroying all affected plants (Cannon et al. 2007). T. palmi is on the EPPO A1 list and regulated as a quarantine pest in the European Union (EPPO 2015). Rapid identification of $T$. palmi is crucial in pest and disease management and quarantine. Several methods have been reported to date for the molecular identification of T. palmi including PCR, RFLP, SCAR marker, multiplex PCR, real-time PCR, LAMP, and monoclonal antibodies (Paran and Michelmore 1993; Banks et al. 1998; Walsh et al. 2005; Yeh et al. 2014; Nakahara and Minoura 2015; Przybylska et al. 2015, 2017; Jangra et al. 2020b). Most of these techniques cannot be done in a farmer's field without access to a laboratory. LAMP can be done in the field but it has limitations for complex primer designing and by non-specific amplification with crude extract. Moreover, LAMP requires either a real-time PCR platform or a heating block for detection, and incubation is required at a higher temperature than that feasible on-site. In the present report, an RPA assay has been standardized for field-based identification of $T$. palmi-a first for detection of an insect. The assay does not require any sophisticated laboratory equipment and can be completed in $20 \mathrm{~min}$ by holding the reaction tubes in one's hand. A LAMP assay reported for identification of T. palmi took at least $30 \mathrm{~min}$ to complete at $63{ }^{\circ} \mathrm{C}$ incubation and analyzed in a real-time PCR machine and/or visualized under UV light (Przybylska et al. 2015). Using RPA, the presence of T. palmi can be quickly determined by the naked eye based on the change in reaction color from dark blue to sky blue.

Out of three primer pairs designed for the assay based on 3' polymorphism at ITS2 region of T. palmi, only one pair (AG117F-AG118R) was shown to be specific to $T$. palmi without cross-reactivity to congeneric thrips species. ITS region refers to the chromosomal spacer DNA situated 
between the small-subunit ribosomal RNA (rRNA) and large-subunit rRNA genes. This hypervariable region has been preferred by several workers for discrimination of thrips at the species level because of a larger interspecific genetic distance than mtCoI (Glover et al. 2010; Przybylska et al. 2015, 2017; Ghosh et al. 2020). Recent reports of several variants of $\mathrm{mtCoI}$ in T. palmi (Iftikhar et al. 2016; Tyagi et al. 2017; Ghosh et al. 2020) were another reason to choose ITS2 over mtCoI in designing the RPA primers.

To use the RPA assay in the farmer's field, an on-site crude DNA extraction protocol from single adult thrips was standardized. Crude DNA was extracted from single thrips by simply crushing in distilled water. This method minimized the time required for insect DNA extraction and could be easily done in the field. The RPA assay reported here was sensitive enough to amplify as little as 0.2 ag of template DNA, $10^{9}$-fold more sensitive than PCR using the same primers. The previously reported sensitivity of real-time PCR for discrimination of T. palmi was $1 \mathrm{pg}$ (Przybylska et al. 2017). The detection threshold for LAMP assay was $2 \times 10^{-10}$ parts of an adult $T$. palmi (Przybylska et al. 2015), whereas the RPA assay could detect as low as $2.9 \times 10^{-13}$ parts of an adult considering $700 \mathrm{ng}$ total DNA extracted from a single adult T. palmi. In summary, the RPA assay developed here is $2 \times 10^{7}$-fold and $>10^{3}$-fold more sensitive than real-time PCR and LAMP, respectively.

The RPA assay was further simplified by using a colorimetric dye to facilitate reaction end-point detection in the field. This negated the requirement of gel electrophoresis. HNB is a metal ion indicator, reported to be useful as a colorimetric indicator for $\mathrm{Mg}^{2+}$ ions (Ito and Ueno 1970). It has been successfully used in LAMP reactions (Goto et al. 2009). HNB was included in the present assay as a novel, inexpensive indicator of the RPA reaction result. The color change from dark blue (negative) to sky blue (positive) is induced by the chelation of $\mathrm{Mg}^{2+}$ ions by dNTPs (Gelfand 1989). The RPA assay using HNB has several advantages over other diagnostic assays including that opening the reaction tubes was not required to read the results, and that results could be easily judged by the naked eye dispensing the use of a UV torch. The on-site assay has been validated and used to identify T. palmi from natural vegetation. Crude DNA extractions could be completed within $15 \mathrm{~min}$, preparing the RPA reaction mixture took less than 5 min followed by $20 \mathrm{~min}$ incubation in the fist. The whole process was completed in $40 \mathrm{~min}$. Hence, this on-site, rapid, and sensitive method for field-based identification of T. palmi can be performed by non-expert personnel without any sophisticated laboratory equipment and will be helpful in quarantine and adopting suitable pest management strategies quickly.

\section{Author contributions}

AG conceived and designed research. PS designed, validated primers, standardized RPA assay. SJ performed cross-reactivity assay, validated the RPA assay, tested field samples. VKB, RGD suggested improvements in the methods. AG analyzed data. PS and SJ wrote the draft manuscript. VKB, RGD critically reviewed the manuscript. AG wrote and edited the final manuscript. RGD redrafted the manuscript, assisted with English language editing. All authors read and approved the manuscript.

Acknowledgements The authors thank Dr. Sunil Kumar Mukherjee (IARI) for providing critical suggestions during the study. The support received from IARI is thankfully acknowledged. This research was also jointly supported by the Queensland Department of Agriculture and Fisheries and the University of Queensland through the Queensland Alliance for Agriculture and Food Innovation.

Funding IARI, Department of Biotechnology (BT/PR26136/ AGIII/103/1005/2018), and Science and Engineering Research Board (EMR/2017/000590).

\section{Compliance with ethical standards}

Conflict of interests The authors declare that they have no conflict of interests.

Ethical approval and consent to participate The samples were collected by the authors from the experimental farm of IARI, New Delhi with permission.

Availability of data and material The datasets generated and/ or analyzed during the current study are available in NCBI database with accession numbers MT984265, MT984266, MT984268, MT984269, MT991561, MT992018, MT992019, MT992026, MT992047, MW020346, MW020349, MW020350, and MW020351.

\section{References}

Banks JN, Collins DW, Rizvi RH, Northway BJ, Danks C (1998) Production and characterization of monoclonal antibodies against the EU-listed pest Thrips palmi. Food Agric Immunol 10:281-290

Bhatti JS (1980) Species of the genus Thrips from India (Thysanoptera). Syst Entomol 5(2):109-166

Cannon R, Matthews L, Collins D (2007) A review of the pest status and control options for Thrips palmi. Crop Prot 26:1089-1098

Cermeli M, Montagne A (1993) Present situation of Thrips palmi Karny (Thysanoptera: Thripidae) in Venezuela. Manejo Integrado de plagas 28:22-23

Cha D, Kim D, Choi W, Park S, Han H (2020) Point of care diagnostic (POCD) method for detecting Bursaphelenchus xylophilus in pinewood using recombinase polymerase amplification (RPA) with the portable optical isothermal device (POID). PLoS ONE 15(1): 0227476

Chisholm IF, Lewis T (2009) A new look at thrips (Thysanoptera) mouthparts, their action and effects of feeding on plant tissue. Bull Entomol Res 74:663-675 
Cluever JD, Smith HA (2017) A photo-based key of thrips (Thysanoptera) associated with horticultural crops in Florida. Fla Entomol 100:454-467

Cooper B (1991) Infestation of the southern yellow thrips Thrips palmi, in vegetables. J Agric Soc Trinidad Tobago 88:37-38

EPPO (2014) PQR database. Paris, France: European and Mediterranean plant protection organization. Available online at https ://www.eppo.int/DATABASES/pqr/pqr.htm

EPPO (2015) A2 list of pests recommended for regulation as quarantine pests EPPO (version 2015-09) Available online at https ://www.eppo.org/QUARANTINE/listA2.html

Folmer O, Black M, Hoeh W, Lutz R, Vrijenhoek R (1994) DNA primers for amplification of mitochondrial cytochrome oxidase subunit I from diverse metazoan invertebrates. Mol Mar Biol Biotechnol 3:294-299

Gelfand DH (1989) Taq DNA polymerase. In: Erlich HA (ed) PCR technology: principles and applications for DNA amplification. Stockton Press, New York, pp 17-22

Ghosh A, Chatterjee ML, Chakraborti K, Samanta A (2009) Field evaluation of insecticides against chilli thrips (Scirtothrips dorsalis Hood). Ann Plant Prot Sci 17:69-71

Ghosh A, Dey D, Timmanna B, Mandal B, Jain RK (2017) Thrips as the vectors of tospoviruses in Indian agriculture. In: Mandal B, Rao GP, Baranwal VK, Jain RK (eds) A century of plant virology in India. Springer, Singapore, pp 537-556

Ghosh A, Basavaraj YB, Jangra S, Das A (2019) Exposure to watermelon bud necrosis virus and groundnut bud necrosis virus alters the life history traits of their vector, Thrips palmi (Thysanoptera: Thripidae). Arch Virol 164(11):2799-2804

Ghosh A, Jagdale SS, Basavaraj, Dietzgen RG, Jain RK (2020) Genetics of Thrips palmi (Thysanoptera: Thripidae). J Pest Sci 93:27-39

Ghosh DK, Kokane SB, Kokane AD, Warghane AJ, Motghare MR, Bhose $S$ et al (2018) Development of a recombinase polymerase based isothermal amplification combined with lateral flow assay (HLB-RPA-LFA) for rapid detection of Candidatus Liberibacter asiaticus. PLoS ONE 13(12):e0208530

Glover RH, Collins DW, Walsh K, Boonham N (2010) Assessment of loci for DNA barcoding in the genus Thrips (Thysanoptera: Thripidae). Mol Ecol Resour 10:51-59

Goto M, Honda E, Ogura A, Nomoto A, Hanaki K (2009) Colorimetric detection of loop-mediated isothermal amplification reaction by using hydroxy naphthol blue. Biotechniques 46:167-172

Guyot J (1988) Review and first observations in Guadeloupe on Thrips palmi Karny. Agronomie 8(7):565-575

Hansen S, SchaEfer J, Fechner K, Czerny C-P, Wahed AAE (2016) Development of a recombinase polymerase amplification assay for rapid detection of the Mycobacterium avium subsp. Paratuberculosis. PLoS ONE 11(12): 0168733

Houston K, Mound L, Palmer J (1991) Two pest thrips (Thysanoptera) new to Australia, with notes on the distribution and structural variation of other species. Aust J Entomol 30:231-232

Iftikhar R, Ashfaq M, Rasool A, Hebert PDN (2016) DNA barcode analysis of thrips (Thysanoptera) diversity in Pakistan reveals cryptic species complexes. PLoS ONE 11:e0146014

Ito A, Ueno K (1970) Successive chelatometric titration of calcium and magnesium using hydroxy naphthol blue (HNB) indicator. Jpn Anal 19:393-397

Jagdale SS, Ghosh A (2019) In silico analyses of molecular interactions between groundnut bud necrosis virus and its vector. Thrips palmi. Virus Dis 30(2):245-251

Jangra S, Dhall H, Aggarwal S, Mandal B, Jain RK, Ghosh A (2020a) An observation on the embryonic development in Thrips palmi (Thysanoptera: Thripidae) eggs obtained by an artificial oviposition setup. J Asia-Pac Entomol 23(2):492-497
Jangra S, Mittal A, Dhall H, Jain RK, Ghosh A (2020b) A multiplex PCR assay for rapid identification of major tospovirus vectors reported in India. BMC Genom 21:170

Johnson MW (1986) Population trends of a newly introduced species, Thrips palmi (Thysanoptera: Thripidae), on commercial watermelon plantings in Hawaii. J Econ Entomol 79(3):718-720

Kapoor R, Srivastva N, Kumari S, Sarithal RK, Sharma SK, Jain RK, Baranwal VK (2017) Development of a recombinase polymerase amplification assay for the diagnosis of banana bunchy top virus in different banana cultivars. Arch Virol 162:2791-2796

Li T-T, Wang J-L, Zhang N-Z, Li W-H, Yan H-B, Li L, Jia W-Z, Fu B-Q (2019) Rapid and visual detection of Trichinella spp. using a lateral flow strip-based recombinase polymerase amplification (LF-RPA) assay. Front Cell Infect Microbiol 9:1

Londono MA, Harmon CL, Polston JE (2016) Evaluation of recombinase polymerase amplification for detection of begomoviruses by plant diagnostic clinics. Virol J 13:48

Ma B, Fang J, Lin W, Yu X, Sun C, Zhang M (2019a) A simple and efficient method for potential point of care diagnosis of human papillomavirus genotypes: combination of isothermal recombinase polymerase amplification with lateral flow dipstick and reverse dot blot. Anal Bioanal Chem 411:7451-7460

Ma L, Zeng F, Huang B, Zhu Y, Wu M, Xu F, Li X, Huang R, Ma J, Cong F, Guo P (2019b) Point of care diagnostic assay for rapid detection of porcine delta coronavirus using the recombinase polymerase amplification method. Transbound Emerg Dis 66:1324-1331

Mandal B, Jain RK, Krishnareddy M, Kumar NKK, Ravi KS, Pappu HR (2012) Emerging problems of tospoviruses (Bunyaviridae) and their management in the Indian subcontinent. Plant Dis 96:468-479

Mehle N, Trdan S (2012) Traditional and modern methods for the identification of thrips (Thysanoptera) species. J Pest Sci 85:179-190

Mekuria TA, Zhang S, Eastwell KC (2014) Rapid and sensitive detection of little cherry virus 2 using isothermal reverse transcription-recombinase polymerase amplification. J Virol Methods 205:24-30

Monteiro RC, Zucchi Ra, Mound LA (1995) Record of Thrips palmi Karny, 1925 (Thysanoptera, Thripidae) in the state of Sao Paulo, Brazil. Revista de Agricultura (Piracicaba) 70(1): 53-55

Mound LA, Gillespie PS (1997) Identification guide to thrips associated with crops in Australia. Orange NSW and Canberra: NSW agriculture and CSIRO https://hdl.handle.net/102.100.100/22081 6 ?index $=1$

Murai T (2002) The pest and vector from east: Thrips palmi. In proceeding of the Thrips and Tospoviruses-PROCEEDINGS of the 7 th international symposium in Thysanoptera. Canberra, Australia national insect collection 19-32

Nakahara S, Minoura K (2015) Identification of four thrips species (Thysanoptera: Thripidae) by multiplex polymerase chain reaction. Res Bull Plant Prot Jpn 42:37-42

Palmer JM (1992) Thrips (Thysanoptera) from Pakistan to the Pacific: a review. Bull Br Mus (Nat Hist) Entomol Ser 61(1):76

Pantoja A, Segarra A, Ruiz H, Medina-Gaud S (1988) Thrips palmi (Thysanoptera: Thripidae): a new insect pest for Puerto Rico. J Agric Univ Puerto Rico 72(2):327

Pappu HR, Jones RAC, Jain RK (2009) Global status of tospovirus epidemics in diverse cropping systems: successes achieved and challenges ahead. Virus Res 141:219-236

Paran I, Michelmore RW (1993) Development of reliable PCR-based markers linked to downy mildew resistance genes in lettuce. Theor Appl Genet 85:985-993

Przybylska A, Fiedler Ż, Frąckowiak P, Obrępalska-Stęplowska A (2017) Real-time PCR assay for distinguishing Frankliniella occidentalis and Thrips palmi. Bull Entomol Res 108:413-420 
Przybylska A, Fiedler Ż, Kucharczyk H, Obrępalska-Stęplowska A (2015) Detection of the quarantine species Thrips palmi by loopmediated isothermal amplification. PLoS ONE 10:e0122033

Reddy DVR, Buiel AAM, Satyanarayana T, Dwivedi SL, Reddy AS, Ratna AS, Vijaylakshmi K, Ranga Rao GV, Naidu RA, and Wightman JA (1995) Peanut budnecrosis virus disease: an overview. In: Recent studies on peanut bud necrosis disease-Proceedings of a Meeting, 20 March.In: Buiel AAM, Parevliet JE, Lenne JM (eds) International crop research institute for semi-arid tropics, Patancheru, Andhra Pradesh, India pp 3-7

Rosser A, Rollinson D, Forrest M, Webster BL (2015) Isothermal recombinase polymerase amplification (RPA) of Schistosoma haematobium DNA and oligochromatographic lateral flow detection. Parasites Vector 8:446

Rotenberg D, Jacobson AL, Schneweis DJ, Whitefield AE (2015) Thrips transmission of tospoviruses. Curr Opin Virol 15:80-89

Seal DR, Kumar V, Kakkar G, Mello SC (2013) Abundance of adventive Thrips palmi (Thysanoptera: Thripidae) population in Florida during the first sixteen years. Fla Entomol 96:789-796

Trdan S, Valič N, Žnidarčič D (2007) Field efficacy of deltamethrin in reducing damage caused by Thrips tabaci Lindeman (Thysanoptera: Thripidae) on early white cabbage. J Pest Sci 80:217

Tyagi K, Kumar V, Singha D, Chandra K, Laskar BA, Kundu S et al (2017) DNA Barcoding studies on Thrips in India: Cryptic species and Species complexes. Sci Rep 7:1-14
Walsh K, Boonham N, Barker I, Collins DW (2005) Development of a sequence specific real-time PCR to the melon thrips Thrips palmi (Thysan., Thripidae). J Appl Entomol 129:272-279

Xi Y, Xu CZ, Xie ZZ, Zhu DL, Dong JM (2019) Rapid and visual detection of dengue virus using recombinase polymerase amplification method combined with lateral flow dipstick. Mol Cell Probes 46:101413

Yadav R, Chang NT (2012) Temperature dependent development and life table parameters of Thrips palmi on eggplant. Appl Entomol Zool 47(4):301-310

Yeh WB, Tseng MJ, Chang NT, Wu SY, Tsai YS (2014) Agronomically important thrips: development of species-specific primers in multiplex PCR and microarray assay using internal transcribed spacer 1 (ITS1) sequences for identification. Bull Entomol Res 105:52-59

Zhao G, He H, Wang H (2019) Use of a recombinase polymerase amplification commercial kit for rapid visual detection of Pasteurella multocida. BMC Vet Res 15:154

Publisher's Note Springer Nature remains neutral with regard to jurisdictional claims in published maps and institutional affiliations. 